\section{MS30-P29 Structure of carbonyl isocyanide complexes with Rhenium and Manganese: carbon monoxyde releasing molecules for biological applications}

Emmanuel Kottelat ${ }^{1}$, Aurélien Crochet $^{1}$, Fabio Zobi ${ }^{1}$

\section{University of Fribourg, Switzerland}

email: emmanuel.kottelat@unifr.ch

CO releasing molecules (CORMs) are widely investigated in synthetic and medicinal chemistry owing to the potential therapeutic applications of the gas. Medical scrutiny of CORMs pivots around treatment of inflammations, microbial infections and organ injuries. Organometallic carbonyl complexes are best suited to play the role of $\mathrm{CO}$ carriers as they allow the exogenous release of $\mathrm{CO}$ under controlled conditions and permit to overcome the toxicity of the gas. With the long-term goal of developing CORMs with similar properties to those of the sesta-methoxyisobutylisonitrile (MIBI) ${ }^{99} \mathrm{~m} \mathrm{Tc}$ complex (Cardiolite), we have studied the reactivity of isocyanide ligands (namely tert-butyl (tbu), isopropyl (ipp), cyclohexyl (chx), S-methylbenzyl (smb), tetramethylbutyl (tmb), and MIBI) towards 16-, $17-$ electron cis- $\left[\operatorname{Re}(\mathrm{CO})_{2} \mathrm{Br}_{4}\right]^{-/ 2-}$ species and the $\left[\mathrm{Mn}(\mathrm{CO})_{5} \mathrm{Br}\right]$ complex. Group 5 metal ions were selected as Re and Mn-based CORMs show low cytotoxicity and demonstrated a protective action against ischemia-reperfusion injuries. A total of 6 different isocyanide ancillary ligands (CNR's), including MIBI, were selected for this study. Their reaction with the cis-dicarbonyl $\operatorname{Re}(\mathrm{III})$ and $\operatorname{Re}(\mathrm{II})$ complexes was accompanied by a 2 or 1 electron reduction of the metal center and resulted in the formation of stable cis-mer- $\left[\mathrm{Re}(\mathrm{CO})_{2} \mathrm{~L}_{3} \mathrm{Br}\right]$ species (where $\mathrm{L}=\mathrm{CNR}$ ), while the same reactions with $\left[\mathrm{Mn}(\mathrm{CO})_{5} \mathrm{Br}\right]$ gave fac- $\left[\mathrm{Mn}(\mathrm{CO})_{3} \mathrm{~L}_{2} \mathrm{Br}\right]$ compounds. All complexes were characterized including single-crystal X-ray diffraction structure determinations. In addition, unique monocarbonyl species were obtained from the reactions of cis- $\left[\mathrm{Re}(\mathrm{CO})_{2} \mathrm{Br}_{4}\right]^{-}$with tert-butyl-isocyanide and cis- $\left[\mathrm{Re}(\mathrm{CO})_{2} \mathrm{Br}_{4}\right]^{2-}$ with MIBI. The species, an heptacoordinated $\operatorname{Re}(\mathrm{III})$ and a hexacoordinated $\operatorname{Re}(\mathrm{II})$ complex, could also be isolated and structurally characterized. The $\mathrm{CO}$ releasing, the cytotoxicity and antibacterial properties of the compounds were also investigated.
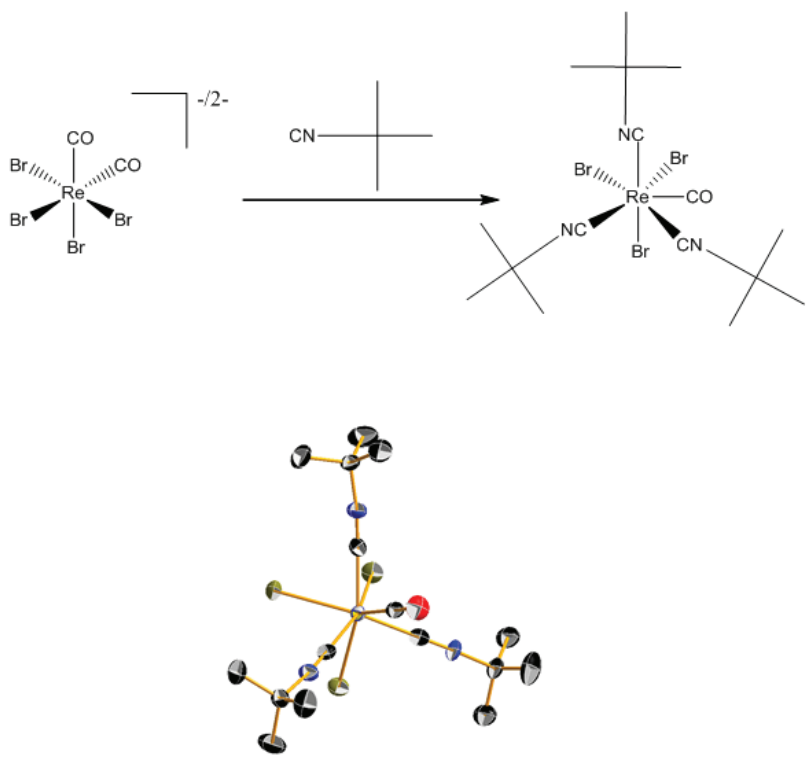

Figure 1. Reaction of $\left[\operatorname{Re}(\mathrm{CO})_{2} \mathrm{Br}^{-/ 2-}\right.$ with tert-butyl isocyanide ligand,giving the heptacoordinated $\mathrm{d}^{4}, 18 \mathrm{e}^{-}$complex

Keywords: CORM, isocyanide, rhenium, manganese, biocompatible 